\title{
Jefferson
}

Thomas Jefferson University

$\overline{\text { HOME OF SIDNEY KIMMEL MEDICAL COLLEGE }}$

Jefferson Journal of Psychiatry

Volume 10 | Issue 1

Article 6

January 1992

\section{The Syndrome of Antidiuretic Hormone Secretion in Psychiatric Patients}

Kathleen Crapanzano, M.D.

Medical College of Georgia, Augusta, Georgia

Follow this and additional works at: https://jdc.jefferson.edu/jeffjpsychiatry

Part of the Psychiatry Commons

Let us know how access to this document benefits you

\section{Recommended Citation}

Crapanzano, M.D., Kathleen (1992) "The Syndrome of Antidiuretic Hormone Secretion in Psychiatric Patients," Jefferson Journal of Psychiatry. Vol. 10 : Iss. 1 , Article 6.

DOI: https://doi.org/10.29046/JJP.010.1.003

Available at: https://jdc.jefferson.edu/jeffjpsychiatry/vol10/iss1/6

This Article is brought to you for free and open access by the Jefferson Digital Commons. The Jefferson Digital Commons is a service of Thomas Jefferson University's Center for Teaching and Learning (CTL). The Commons is a showcase for Jefferson books and journals, peer-reviewed scholarly publications, unique historical collections from the University archives, and teaching tools. The Jefferson Digital Commons allows researchers and interested readers anywhere in the world to learn about and keep up to date with Jefferson scholarship. This article has been accepted for inclusion in Jefferson Journal of Psychiatry by an authorized administrator of the Jefferson Digital Commons. For more information, please contact: JeffersonDigitalCommons@jefferson.edu. 


\title{
The Syndrome of Antidiuretic Hormone Secretion in Psychiatric Patients
}

\author{
Kathleen Crapanzano, M.D.
}

\begin{abstract}
The syndrome of inappropriate secretion of antidiuretic hormone (SIADH) is a common medical illness which has many etiologies - some of which are particular to psychiatric patients. This review will discuss the diagnosis of SIADH and then the various etiologies for its development with emphasis on those which are more relevant to psychiatric patients. Future research will be directed to a further understanding of this disorder, as well as to treatment options to decrease the significant morbidity associated with this condition.
\end{abstract}

"Is it only the mouth and the belly which are injured by hunger and thirst? Men's minds are also injured by them."

Mencius, Works, Book VII 372-289 BC

\section{INTRODUCTION}

Disorders of water metabolism in psychiatric patients have been noted since the early part of the century. The results of physiological studies of schizophrenia in the 1930's (1-4) have become the basis for all future research in this area. In these early studies, the findings of increased urine volumes in schizophrenics were unexpected and of unknown significance, and some sixty years later, the questions raised in these studies remain largely unanswered. Much of what has been published in this area, however, has implicated the role of antidiuretic hormone (ADH) or arginine vasopressin (AVP). This paper will review the diagnosis of SIADH and discuss its etiologies with emphasis on a psychiatric population. The topic of psychogenic polydipsia will be touched upon, but the reader is referred to a review by Illowsky and Kirch (5) for a thorough discussion of the subject.

The finding of a disturbed water regulatory system in the psychiatric population has been labelled by such terms as self-induced water intoxication, compulsive polydipsia, psychogenic polydipsia, and primary polydipsia. Far from being a simple problem of drinking too much, the disorders of water metabolism are the result of permutations of the delicate balance of renal, endocrine, cardiac and thirst systems of the body. Future work in this area will hopefully elicit the answers to the numerous questions that will be raised in this paper. 


\section{PHYSIOLOGY OF ADH}

The pathological states of antidiuretic hormone include both absence and excess. Diabetes insipidus is a physiological absence or lowering of ADH. In central diabetes insipidus, there are defects in the synthesis and/or secretion of ADH. Depending on the severity of the disease, polydipsia/polyuria from 3-20 liters in 24 hours will result. Patients generally have a preference for cold water, and there is little diurnal variation in their symptoms. With an intact thirst mechanism, patients can remain asymptomatic, but without an intact thirst mechanism, life-threatening water depletion and hypernatremia can result. In nephrogenic diabetes insipidus, no significant urinary concentration occurs in spite of normal circulating levels of antidiuretic hormone. A clinical picture similar to central diabetes insipidus occurs.

Generally, hyponatremia is the result of an impairment in renal water excretion due to an excess of $\mathrm{ADH}$ secretion or some intrarenal abnormality in urine dilution (6). Hyponatremia with a decrease in osmolarity should be questioned for error or pseudohyponatremia. Hyponatremia associated with an increased total body sodium will occur in patients with an increase in body sodium, but a larger increase in body water. Generally, there is a decrease in effective blood volume, caused by conditions such as congestive heart failure, hepatic cirrhosis, and nephrotic syndrome. Hyponatremia with a decreased total body sodium is generally also hypovolemic, and can be seen in advanced chronic renal insufficiency, medullary cystic disease, polycystic kidney disease, the use of diuretics, or adrenal insufficiency. Hyponatremia with clinically undetectable alterations in body sodium should alert the clinician for the possibility of SIADH, but, in addition, emotional stress, hypothyroidism, and medication effects should be considered. The syndrome of inappropriate secretion of antidiuretic hormone is defined by the following criteria proposed by Bartter and Schwartz (7):

1. Hyponatremia or hypoosmolarity of plasma and extracellular fluid

2. Renal sodium loss

3. Absence of clinical evidence of fluid volume excess or depletion

4. Osmolarity of the urine greater than appropriate for the concomitant tonicity of the plasma (i.e., urine is less than maximally dilute)

5. Normal renal and adrenal function.

A sixth criteria is the actual measure of $\mathrm{ADH}$ levels, which is now available by assay.

\section{EVIDENCE FOR ADH DYSFUNCTION IN PSYCHIATRIC PATIENTS}

There is much evidence in the literature that there are subgroups of psychiatric patients in general and schizophrenic patients in particular that handle water metabolism defectively $(1-4,8-13)$.

In a series of studies examining the physiology of schizophrenia approximately sixty years ago, significantly before the advent of psychotropic medications, Hoskins, Sleeper, and Jellinik (1-4) showed urine output of schizophrenic subjects to be 
consistently double that of normal controls. Although Hoskins and Sleeper originally concluded an organic basis to their findings, only three years later Sleeper and Jellinek state "the explanation of the polyuria seems to reside more in the psychical than in the physiological or the biochemical domain." The finding of polyuria in schizophrenia has been largely ignored in the literature until recently, and repeat studies in the modern era have shown similar findings (14).

Numerous case reports have been published which establish the propensity some psychiatric patients have to handle water loads inappropriately (15-18). The conclusions of these reports have invariably been that a state of antidiuretic hormone excess exists with or without a concomitant state of polydipsia. Studies actually measuring $\mathrm{ADH}$ under various conditions have been few. Raskind et al. (19) is the first to have measured antidiuretic hormone levels in acutely psychotic patients. All the subjects were nonsmokers and were off psychotropic medications for four weeks. The results of the measurements suggest elevations of $\mathrm{ADH}$, which are postulated to occur during psychotic illness and produce hyponatremia in polydipsic patients. Vieweg et al. $(20,21)$ report at least six patients with polydipsia, hyponatremia, and SIADH who have elevated levels of $\mathrm{ADH}$ on random blood evaluations. All the patients were smokers, however, which complicates these findings as nicotine is a known potent stimulator of $\mathrm{ADH}$ release (22).

Goldman et al. (8) report three findings as a result of their evaluation of polydipsic schizophrenic patients with water load testing and a hypertonic saline load-an enhanced renal sensitivity to ADH, a lowered osmotic threshold for release of $\mathrm{ADH}$, and a disturbance in thirst regulation. Emsley et al. (9) gave a standard water load test to 23 unmedicated psychotic patients who did not display polydipsia and found smaller urine output and higher minimum urine osmolalities in the psychiatric patients over the controls in his study. However, there is a significant correlation between anxiety measurements and vasopressin levels. Because of this, the authors postulate emotional stress may play a role in the measured $\mathrm{ADH}$ elevations.

Kishimoto et al. (10) also measured $\mathrm{ADH}$ levels in psychiatric patients. In the study, $\mathrm{ADH}$ is measured in schizophrenic patients with and without hyponatremia. The authors observe that the sensitivity of $\mathrm{ADH}$ response to osmolality is decreased in schizophrenic patients, regardless of the presence of hyponatremia. In summary, Kishimoto postulates that the primary low sensitivity of the osmoreceptors in addition to the renal hypersensitivity postulated by Goldman may combine to cause SIADH and thereby impair excretion of free water.

To review, there have been many case reports of psychiatric patients with laboratory findings that imply a state of $\mathrm{ADH}$ excess. The studies that have documented this are few and contradictory. Raskind et al. and Vieweg et al. have documented cases of elevated $\mathrm{ADH}$, whereas Goldman et al. did not, under more controlled conditions. Emsley et al. found an elevated resting $\mathrm{ADH}$ in psychotic patients who were anxious, but a normal ADH response to water loading. Kishimoto et al. found a decreased sensitivity of $\mathrm{ADH}$ secretion, similar to the findings of Goldman et al. The one consistent finding, however, is an impairment of free water 
clearance and an impairment of urine dilution with or without elevation of ADH in psychotic subgroups.

\section{SIADH AND ITS MULTIPLE CAUSES IN PSYCHIATRIC PATIENTS}

\section{Medical Conditions}

There are a multitude of medical conditions that can cause SIADH including pulmonary disease, malignant tumors (commonly of the lung and rarely of the duodenum and pancreas), porphyria, disorders of the central nervous system (meningitis, head injuries, brain abscess, intracranial tumors, encephalitis, subarachnoid hemorrhage), infectious diseases including pneumonia, tuberculosis, and aspergillosis, congestive heart failure, Addison's disease, hypothyroidism, cirrhosis of the liver, and postoperative states.

\section{Medications}

Many medications have been found to produce SIADH including acetaminophen, chlorpropamide, tolbutamide, diuretics, vincristine, cyclophosphamide, and clofibrate. More germane to this discussion are the reports of psychiatric medications that cause SIADH.

There are 41 case reports of heterocyclic antidepressant-induced SIADH in the literature (23). The vast majority are secondary to tricyclic antidepressants, but fluoxetine is represented as well as monamine oxidase inhibitors.

Haloperidol (24), thioridazine $(25,26)$, thiothixene (27), and fluphenazine (28) have been reported on the literature to cause SIADH. If the antipsychotic medications do contribute to the development of SIADH, the mechanism of this would be difficult to understand. Sklar and Schrier (29) write that traditional antipsychotic drugs, all dopamine-receptor antagonists, should suppress psychic and hormonal expressions of the disease if the reason for SIADH in psychiatric patients is excessive central dopaminergic neurotransmission. This makes it difficult to explain why antipsychotics could cause a state of ADH excess. Kishimoto et al. (10) show that chronic neuroleptic administration causes a reversible increase in the sensitivity of $\mathrm{ADH}$ secretion in their study on rabbits. However, this is not confirmed in his human studies. They conclude that low sensitivities of osmoreceptors in the psychiatric population are determined by unknown genetic or biologic factors rather than neuroleptic medications. Raskind et al. (30) found that injections of antipsychotic drugs do not elevate vasopressin, except through the baroreceptor reflex mechanism of hypotension. In fact, they found a normalization of elevated $\mathrm{ADH}$ in two psychotic patients after antipsychotic medication treatment.

Carbamazepine-induced hyponatremia is well established in the literature. Lahr (31) shows a $21.7 \%$ prevalence of hyponatremia in patients taking carbamazepine in a study of epileptic patients who were also mentally retarded. It is thought that 
carbamazepine stimulates the release of $\mathrm{ADH}$, and it has been used successfully in the treatment of patients with diabetes insipidus.

\section{Nicotine}

The role of nicotine in SIADH in the psychiatric population is an important one. Recent evidence suggests that psychiatric patients smoke more than the general public (32) for largely unknown reasons. As Husain et al. (22) report, nicotine is a potent stimulus for both vasopressin and neurophysin release in some, but not all, normal individuals. In an epidemiological study designed to better define the characteristics of patients at risk for self-induced water intoxication, Jose and Evenson (60) found that $69 \%$ of these patients were smokers.

Blum (34) reports a case of SIADH in a psychiatric patient with a long history of polydipsia, smoking, schizophrenia, and treatment with neuroleptics. With ad lib water intake and no cigarettes, this patient was able to maintain his normal sodium levels; limited smoking caused a modest drop in his sodium, and ad lib smoking resulted in hyponatremia. Similarly, Chin (35) reports a case of a compulsive water drinker with the syndrome of inappropriate secretion of $\mathrm{ADH}$ who also had a normal water loading test with no cigarettes, but whose excretion dropped to $26 \%$ during a repeat test with the administration of 15 cigarettes. Using two schizophrenic patients with a history of water intoxication and six normal controls, Allon et al. (36) postulate that cigarette use may contribute to hyponatremia, since water excretion was impaired in both groups after nicotine use.

Nicotine has a very potent effect on the release of $\mathrm{ADH}$ from the posterior pituitary in normal, as well as psychiatric patients. While it is not necessary for a patient to be a cigarette smoker (or tobacco ingestor) to develop hyponatremia, the use of cigarettes in a susceptible patient, defined as a psychiatric patient with impaired water excretory mechanisms, may be sufficient to induce hyponatremia and its consequences.

\section{Psychosis and Affective Disorders}

There has been a reported association between affective disorders and SIADH (11-13). However, in the six reported cases, five of the patients were psychotic, and at least three were polydipsic. This calls into question whether the SIADH is secondary to some aspect of the psychotic process or the affective disorder itself.

There have been quite a few case reports associating psychosis and SIADH. Targowla (37) notes acute psychotic patients with water retention that improved with improvement in their psychosis. Multiple researchers (17,18,22,38-43) report cases of SIADH in psychotic patients, suggesting a link between the two entities. Dubovsky et al. (44) present an interesting case of a person whose SIADH appeared and remitted in conjunction with his psychotic symptoms. Shen et al. (45) and Jones (46) propose that instead of a cause and effect relationship between psychosis and SIADH, that SIADH is a dopaminergic supersensitivity phenomenon induced by 
neuroleptic exposure and/or neuroleptic withdrawal. Although this is an interesting hypothesis worthy of evaluation, the physiological studies of schizophrenic patients (1-4) conducted prior to the advent of antipsychotic medications weaken this argument. In addition, Barahal's (47) published case of water intoxication was prior to the use of medications. In contrast to the above, Fowler et al. (41) present the idea that nonspecific stress can increase $\mathrm{ADH}$ release in animals and may be operative in psychotic illness; this theory was supported by Emsley et al. (9).

\section{"Psychogenic Polydipsia"}

The evidence at this point does not support psychogenic polydipsia as a cause of SIADH, but rather as a coexisting condition. This population of psychiatric patients who comprise somewhere between $6.6 \%$ and $17.5 \%$ of psychiatric patients $(48,49)$ has shown a defect in free water clearance and urinary concentrating ability that meets the criteria for SIADH, but which alone are insufficient to account for the severe episodes of hyponatremia and hypoosmolarity that these patients periodically suffer. In addition, psychogenic polydipsic patients are a heterogenous group with some exhibiting polydipsia without episodes of hyponatremia, some having lower threshold for $\mathrm{ADH}$ release (reset osmostat), and some becoming intermittently hyponatremic. It is unclear whether these different clinical presentations of polydipsic patients are part of the natural history of the water regulatory disturbance, whether these are different clinical expressions of the same illness, or whether these are different conditions all together. Raskind et al. (30) propose a unitary disturbance of limbic system function to produce the clinical picture of psychosis, polydipsia, and SIADH. He notes the close relationship between the limbic system components involved in behavior, central regulatory sites for water drinking behaviors, and the nuclei responsible for the release of $\mathrm{ADH}$.

$E C T$

In the various case reports of SIADH and polydipsia, ECT is a common treatment modality (50-52). The role that ECT may play in the development of SIADH is unclear, however. Finlayson et al. (52) report a case of hyponatremia after ECT and postulate that the hyponatremia is secondary to polydipsia. However, another possibility is that the seizure activity deregulates the thirst mechanisms and stimulates the release of $\mathrm{ADH}$ (53), causing, in combination, the clinical picture of SIADH with polydipsia and resultant hyponatremia.

\section{DISCUSSION}

In evaluating a patient with possible SIADH, the diagnosis must first be established according to the criteria of Bartter and Schwartz (7) discussed earlier. Once the diagnosis is established, the etiology for the disorder must be sought. The work up should include a thorough history and physical examination, blood work to 
include blood chemistry, complete blood count, liver function tests, thyroid function tests, and an AM cortisol. A chest X-ray, as well as a CT scan of the head to rule out central nervous system pathology are necessary. The next step would be to investigate the use of nicotine and any medications the patient is taking. If a medication is implicated in the causation of SIADH, it should be rechallenged to the patient to assure that it is responsible for the clinical presentation of the patient. A consultant could be called at this point for further suggestions in evaluation and for assistance with treatment. Only after the above diagnostic workup can the patient's SIADH be attributed to his psychiatric condition.

SIADH is common in a psychiatric population for a number of reasons that have been discussed. Because of the serious complications that can develop from SIADH if it is unrecognized (such as hyponatremia, seizures, coma, and death), this condition should be aggressively evaluated and treated. For a review of the treatment of water metabolism disorders in psychiatric patients, the reader is referred to a recent review by Goldman on the subject (54).

The area of water metabolic disorders in psychiatric patients is one with numerous avenues for research available. As seen in this review, much of what is published in this area is purely anecdotal and based on case reports. Those studies which have attempted to further evaluate the problem often report results on fewer than ten patients. One area in particular that needs to be explored in detail is a thorough scrutiny of all parameters involved in water metabolism, not just ADH measurements. The effects of long term polydipsia have only begun to be explored (54), and further studies need to be initiated, particularly exploring the effects on the kidney. To that end, studies evaluating the natural history of the illness should be attempted. Finally, treatment options to be explored include angiotensin-converting enzyme inhibitors, which decrease angiotensin II stimulated thirst, bromocriptine, a dopamine receptor agonist, (because of its effect on decreasing thirst), and calcium channel blockers to decrease calcium influx and subsequent ADH release (29).

\section{REFERENCES}

1. Hoskins RG: Schizophrenia from the physiological point of view. Ann Int Med 7:445-456, 1933

2. Hoskins RG, Sleeper F: Organic functions in schizophrenia. Arch Neur Psyc 30:123-140, 1933

3. Sleeper FH: Investigation of polyuria in schizophrenia. Am J Psyc 91:1019-1031, 1935

4. Sleeper F, Jellinek E: A comparative physiologic, psychologic, and psychiatric study of polyuric and nonpolyuric schizophrenic patients. J Nerv Ment Dis 83:557-563, 1936

5. Illowsky B, Kirch D: Polydipsia and hyponatremia in psychiatric patients. Am J Psyc 145:675-683, 1988

6. Berl T, Anderson R, McDonald K, et al: Clinical disorders of water metabolism. Kidney Int 10:117-132, 1976

7. Bartter FC, Schwartz WB: The syndrome of inappropriate secretion of antidiuretic hormone. Am J Med 42:790-806, 1967 
8. Goldman M, Luchins D, Robertson G: Mechanisms of altered water metabolism in psychotic patients with polydipsia and hyponatremia. N Engl J Med 318:397-403, 1988

9. Emsley R, Potgieter A, Taljaard F, et al: Water excretion and plasma vasopressin in psychotic disorders. Am J Psych 146:250-253, 1989

10. Kishimoto T, Hirai M, Ohsawa H, et al: Manners of arginine vasopressin secretion in schizophrenic patients - with reference to the mechanism of water intoxication. Jap J Psyc Neur 43:161-169, 1989

11. Zubenko G, Altesman R, Cassidy J, et al: Disturbances of thirst and water homeostasis in patients with affective illness. Am J Psyc 141:436-437, 1984

12. Brown R, Kocsis J, Cohen S: Delusional depression and inappropriate antidiuretic hormone secretion. Biol Psyc 18:1059-1063, 1983

13. MacMillan H, Gibson J, Steiner M: Hyponatremia and depression. J Nerv Ment Dis 178:720-722, 1990

14. Lawson WB, Karson CN, Bigelow LB: Increased urine volume in chronic schizophrenic patients. Psych Res 14:323-331, 1985

15. Rosenbaum JF, Rothman JS, Murray GB: Psychosis and water intoxication. J Clin Psyc 40:287-291, 1979

16. Kramer DS, Drake ME: Acute psychosis, polydipsia, and inappropriate secretion of antidiuretic hormone. Am J Med 75:712-714, 1983

17. Singh S, Padi M, Bullard H, et al: Water intoxication in psychiatric patients. Br J Psych 146:127-131, 1985

18. Tallis GA: Hyponatremia in psychiatric patients. Med J Aus 150:151-153, 1989

19. Raskind M, Weitzman R, et al: Is antidiuretic hormone elevated in psychosis? Biol Psyc 13:385-390, 1978

20. Vieweg WVR, Rowe WT, David JJ, et al: Hyposthenuria as a marker for self-induced water intoxication and schizophrenic disorders. Am J Psyc 141:1258-1260, 1984

21. Vieweg WVR, Rowe WT, David JJ, et al: Evaluation of patients with self-induced water intoxication and schizophrenic disorders. J Nerv Ment Dis 172:552-555, 1984

22. Husain M, Frantz A, Ciarochi F, et al: Nicotine-stimulated release of neurophysin and vasopressin in humans. J Clin End Meta 41:1113-1117, 1975

23. Crapanzano KC, Sunde DA: Heterocyclic antidepressant-induced SIAD. In progress

24. Husband C, Mai FM, Carruthers G: Syndrome of inappropriate secretion of antidiuretic hormone in a patient treated with haloperidol. Can J Psyc 26:196-197, 1981

25. Fischman C: Water intoxication and thioridazine. Ann Int Med 82:852, 1975

26. Vincent FM, Emery S: Antidiuretic hormone syndrome and thioridazine. Ann Int Med 89:147-148, 1978

27. Ajlouni K, Kern M, Tures J, et al: Thiothixene-induced hyponatremia. Arch Intern Med 134:1103-1105, 1974

28. DeRivera JLG: Inappropriate secretion of antidiuretic hormone from fluphenazine therapy. Ann Int Med 82:811-812, 1975

29. Sklar A, Schrier R: Central nervous system mediators of vasopressin release. Physiol Rev 63:1243-1280, 1983

30. Raskind MA, Courtney N, Murburg MM, et al: Antipsychotic drugs and plasma vasopressin in normals and acute schizophrenic patients. Biol Psyc 22:453-462, 1987

31. Lahr MB: Hyponatremia during carbamazepine therapy. Clin Pharmacol Ther 37:693696, 1985

32. Menza MA, Grossman N, Van Horn M, et al: Smoking and movement disorders in psychiatric patients. Biol Psyc 30:109-115, 1991 
33. Jose CJ, Evenson RC: Antecedents of self-induced water intoxication: A preliminary report. J Nerv Ment Dis 168:498-500, 1980

34. Blum A: The possible role of tobacco cigarette smoking in hyponatremia of long-term psychiatric patients. JAMA 252:2864-2865, 1984

35. Chin WW, Cooper DS, Crapo L: Water intoxication caused by smoking in a compulsive water drinker. Clin Res 24:625, 1976

36. Allon M, Allen H, Deck L, et al: Role of cigarette use in hyponatremia in schizophrenic patients. Am J Psyc 1075-1077, 1990

37. Targowla R: Des troubles fonctionnels du rein dans les maladies mentales. l'excretion de l'eau. Bull Soc Med Hop Paris 47:1711, 1923

38. Hobson J, English J: Self-induced water intoxication. Ann Int Med 58:324-332, 1963

39. Raskind M: Psychosis, polydipsia, and water intoxication. Arch Gen Psyc 30:112, 1974

40. Raskind M, Orenstein H, Christopher T: Acute psychosis, increased water ingestion, and inappropriate antidiuretic hormone secretion. Am J Psych 132:907-910, 1975

41. Fowler R, Kronfol Z, Perry P: Water intoxication, psychosis, and inappropriate secretion of antidiuretic hormone. Arch Gen Psyc 34:1097-1099, 1977

42. Henn F: Dopamine and schizophrenia. Lancet 1:293-295, 1978

43. Khamnei A: Psychosis, inappropriate antidiuretic hormone secretion, and water intoxication. Lancet 1:963, 1984

44. Dubovsky S, Grabon S, Berl T, et al: Syndrome of inappropriate secretion of antidiuretic hormone with exacerbated psychosis. Ann Int Med 79:551-554, 1973

45. Shen W, Baig M, Sata L, et al: Dopamine receptor supersensitivity and the chemoreceptor trigger zone. Biol Psyc 18:917-921, 1983

46. Jones B: Psychosis associated with water intoxication: psychogenic polydipsia or concomitant dopaminergic supersensitivity disorders? Lancet 1:519-520, 1984

47. Barahal H: Water intoxication in a mental case. Psych Q 12:767-771, 1938

48. Jose CJ, Perez-Cruz J: Incidence and morbidity of self-induced water intoxication in state mental hospital patients. Am J Psyc 136:221-222, 1979

49. Blum A, Tempey F, Lynch W: Somatic findings in patients with psychogenic polydipsia. J Clin Psyc 44:55-56, 1983

50. Brant RH, Chodroff C: ECT as a possible treatment for SIADH: case report. J Clin Psyc 43(2):73-74, 1982

51. Gipson T, Price T: Inappropriate ADH secretion in a psychiatric setting. Psyc Opinion 15:43-46, 1978

52. Finlayson J, Viewig W, Wilkey W, et al: Hyponatremic seizure following ECT. Can J Psyc 34:463-464, 1989

53. Aminoff MJ, Simon RP, Wiedemann E: The hormonal responses to generalized tonicclonic seizures. Brain 107:569-578, 1984

54. Goldman MB: A rational approach to disorders of water balance in psychiatric patients. Hosp Comm Psyc 42:488-494, 1991 